\title{
Identification of a Ty1 Regulatory Sequence Responsive to STE7 and STE12
}

\author{
MAHSHID COMPANY, † CAROLINE ADLER, AND BEVERLY ERREDE* \\ Department of Chemistry, University of North Carolina, Chapel Hill, North Carolina 27514
}

Received 11 December 1987/Accepted 9 February 1988

\begin{abstract}
Ty1 activation of gene expression observed in haploid cell types of Saccharomyces cerevisiae requires the STE7 and STE12 gene products. An activator sequence within Ty1 that is responsive to these two regulators has been defined. Complex formation between a factor in whole-cell extracts and the DNA regulatory element showed the same dependence on the STE7 and STE12 gene products as did reporter gene expression. Base pair substitutions within the binding site abolished the ability to form the factor-DNA complex and to activate gene expression. The correlation between complex formation and reporter gene expression indicates that factor binding to the cis-acting element is essential for gene activation. Because the predicted protein for the STE7 gene product is homologous to protein kinases, we suggest that protein phosphorylation may directly or indirectly regulate formation of this DNA-protein complex.
\end{abstract}

Eucaryotic cells differentiate into distinct cell types that express characteristic subsets of genes and are able to perform specialized functions. Regulation at the transcriptional level is one of the primary steps for control of cell-type-specific gene expression. Existing evidence indicates that transcriptional control involves interactions between specific DNA recognition elements, site-specific DNA-binding proteins, and the transcriptional machinery (for reviews, see references 8,28 , and 37). In general, eucaryotic promoters appear to be a mosaic of distinct DNA recognition elements that function in different combinations to achieve specific patterns of gene expression reflecting inducible, positive, or negative controls. Proteins that bind to specific DNA sequences have been identified in many systems, and some have been purified. However, the mechanisms that regulate formation of these DNA-protein complexes and the mechanisms by which the complexes affect gene expression are not understood.

Saccharomyces cerevisiae is a model for the study of events controlling cell type specialization. Although this yeast is a unicellular organism, it exhibits three cell types. The a and $\alpha$ haploid cell types are specialized to mate with each other, and the a/ $\alpha$ diploid cell type is specialized for meiosis and sporulation (for reviews, see references 22 and 31). The a or $\alpha$ alleles present at the mating type locus (MAT) are the primary determinants of cell type. The $\alpha$ allele encodes two site-specific DNA-binding proteins, $\alpha 1$ and $\alpha 2$, that regulate the steady-state abundance of mRNA from cell-type-specific genes $(2,20,25)$. The a allele encodes the a1 regulatory protein. Expression of both a1 and $\alpha 2$ in the diploid cell type causes repression of haploid specific genes.

The specialized function of mating between haploid cell types requires intercellular recognition followed by cell and nuclear fusion to form a diploid cell. Expression of the genes required for these functions depends on several regulatory determinants in addition to those encoded at MAT. Some of the regulators have been identified by sterile mutations that prevent mating in both haploid cell types. The STE7, STE11, and $S T E 12$ genes are among this group (21). The involve-

\footnotetext{
* Corresponding author.

$\dagger$ Present address: Division of Biology 147-75, California Institute of Technology, Pasadena, CA 91125.
}

ment of STE7, STE11, and STE12 in regulation of gene expression was first suggested by studies on Ty1 insertion mutations $(9-11,45)$. Recently, it was shown that each of these three $S T E$ gene products is required for full expression of several a- and $\alpha$-specific genes (14). The nucleotide sequences for the $S T E 7, S T E 11$, and $S T E 12$ genes have been determined (46; L. Connell and B. Errede, unpublished data; S. Fields, personal communication; G. Ammerer, personal communication). The predicted $S T E 7$ and $S T E 11$ proteins show significant homology to members of the protein kinase family (46; Connell and Errede, unpublished).

The $\mathrm{CYC7}-\mathrm{H} 2$ gene is a convenient reporter for cell-typespecific gene expression in $\mathrm{S}$. cerevisiae. The $\mathrm{CYC7}-\mathrm{H} 2$ allele was caused by insertion of the transposable element, Ty1, into the 5'-noncoding region of the $C Y C 7$ structural gene for iso-2-cytochrome $c$. The Ty1 insertion causes haploid-specific overproduction of iso-2-cytochrome $c$. The overproduction in haploid cell types is abolished by mutations at STE7, STE11, or STE12 (9-11). Mutational analysis of the $\mathrm{CYC7}-\mathrm{H} 2 \mathrm{Ty} 1$ indicates that multiple regulatory elements within Ty1 are responsible for the observed pattern of cell-type-specific gene expression $(5,13)$. Two regions of Ty1 (A and D; Fig. 1) were identified that are sufficient to mimic the regulation of adjacent gene expression characteristic of the complete Ty1 (5). Region D includes the element designated block II which has overlapping homology to the simian virus 40 enhancer and to the "a1- $\alpha 2$ " repressor site found at several haploid-specific genes $(12,30,35,41,42)$. Block II and various fragments encompassing the block II element have been analyzed and shown to function as a haploid-specific enhancer in $S$. cerevisiae (13; unpublished observations). Region A was found to function as an activator of adjacent gene expression.

In this report, the region A activator has been examined in more detail. We initiated investigations into regulation of the activator by focusing on two of the three $S T E$ gene products known to affect Tyl activation of gene expression. The STE7 gene was chosen as representative of regulation by a possible protein kinase, and STE12 was chosen as representative of a distinct class. We have not yet investigated effects of other $S T E$ gene products on region A function. Results showed that function of the region $A$ activator is regulated by both the $S T E 7$ and $S T E 12$ gene products. Several specific 


\section{CYC7-H2}

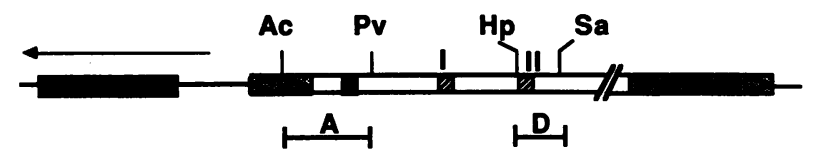

CYC7-H69

200 bp

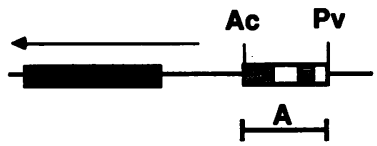

FIG. 1. Schematic structure of $\mathrm{CYC7}-\mathrm{H} 2$ and $\mathrm{CYC7}-\mathrm{H} 69$ alleles. $C Y C 7$ coding sequences are shown by solid boxes. Thick lines represent $C Y C 7$ flanking sequences. The arrow above $C Y C 7$ indicates the polarity and extent of the $C Y C 7$ transcription unit. Delta sequences are shown by stippled boxes. The U5 domain of delta sequences is shown by a triangle. The open boxes represent epsilon sequences. The diagonally hatched boxes identify block I and block II sequences which have homology to the simian virus 40 enhancer and to the MAT $\alpha$ a1- $\alpha 2$ site (12). Horizontal hatching identifies the STE7 and STE12 responsive element. Restriction sites identifying fragment $\mathrm{A}$ and D boundaries are AccI (Ac)-PvuII (Pv) and $\mathrm{HpaI}$ (Hp)-Sau3A (Sa), respectively.

protein-DNA complexes form with region A DNA. Formation of one of these depends on the function of the STE7 and $S T E 12$ gene products. The DNA recognition element for the $S T E$-dependent protein-binding interaction is defined.

\section{MATERIALS AND METHODS}

Plasmids. pNC149 carries the ste7- $43:: U R A 3$ allele which was constructed as follows. A 5.2-kilobase (kb) SacI fragment of STE7 from pSTE7.4 was inserted into the SacI site of pUC118-1 (46). pUC118-1 is a pUC118 derivative in which the HindIII site of the polylinker was destroyed (47). The 3.1-kb region of $S T E 7$ that is contained within two adjacent HindIII fragments was deleted. This segment encompasses the entire STE7-coding region (46). A 1.2-kb HindIII URA3 fragment from pLG669-Z was inserted at the HindIII deletion junction (19). pNC163 carries the ste 12- $\triangle 1:: U R A 3$ allele which was constructed as follows. A $5.5-\mathrm{kb}$ ClaI fragment of STE12 from pSC4 was inserted at the ClaI site of pBR322 (3, 15). A 2.5-kb SacI fragment of STE12 was deleted. The SacI fragment was shown to be sufficient for complementation of a ste 12 mutation so that it presumably includes most of the coding region (15). After appropriate end repair, the $1.2-\mathrm{kb}$ URA3 fragment was inserted at the SacI deletion junction. pNC98 is a pUC118 derivative that carries CEN3, ARS1, $T R P 1$, and $C Y C 7$ yeast sequences. A polylinker cloning site replaces nucleotides -200 to -290 of the $C Y C 7$ gene. pNC105 contains the AccI-PvuII fragment from the CYC7H2 Ty1 inserted at the pNC98 polylinker. Construction of pNC98 and pNC105 was described previously (5). pNC188 contains the Sau3A-PvuII fragment from the CYC7-H2 Ty1 inserted at the pNC98 polylinker. pNC175 and pNC189 are analogous constructions with the corresponding fragments from a variant Ty1 inserted at the pNC98 polylinker. pNC156 and pNC157 are plasmids representing the two orientations of the AccI-PvuII fragment from the CYC7-H2 Ty1 inserted at the HincII site of pUC118. pNC155 and pNC156 are the analogous pUC118 derivatives with the variant Tyl AccI-PvuII fragment inserted at the HincII site.
Yeast strains and genetic procedures. $S$. cerevisiae haploid strains E724-7A (MATa cycl-11 cyc7-67 gal2 canl trpl-289 ura3-52), E906-8B (MATa cycl-11 cyc7-67 canl leu2-3,112

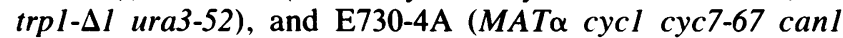
his5 leu2 trpl) used in this study have been described previously $(4,13)$. Isogenic $C Y C 7-H 2$ and $C Y C 7-H 69$ yeast strains were constructed from E724-7A by gene replacement (34). E724-7A-1 ( CYC7-H2) was constructed with the 7.5-kb HindIII fragment from pAB35 (9). E724-7A-5 (CYC7-H69) was constructed with the 2.4-kb SalI fragment from pNC69 (5). Isogenic ste7- $\Delta 3$ derivatives of E724-7A-1 and E724-7A5 were constructed by replacement of the $S T E 7^{+}$allele with the 4.4-kb SacI fragment from pNC149 that contains the ste7- $\triangle 3:: U R A 3$ allele. The resulting strains are designated E724-7A-2 (CYC7-H2 ste7- $\triangle 3:: U R A 3)$ and E724-7A-6 (CYC7H69 ste 7- $\triangle 3:: U R A 3)$. Similarly, isogenic ste $12-\Delta l$ derivatives were constructed by replacement of the $S T E 12^{+}$allele with the 5.5-kb ClaI fragment from pNC163 that contains the ste 12- $\triangle 1:: U R A 3$ allele. The resulting strains are designated E724-7A-4 (CYC7-H2 ste 12- $\triangle 1:: U R A 3)$ and E724-7A-8 (CYC7H69 ste 12- $\Delta I:: U R A 3)$. A ste 12- $\Delta l$ derivative of E906-8B was constructed by gene replacement with the $5.5-\mathrm{kb}$ ClaI fragment from pNC163. The resulting strain is designated E906-8B-8 (cyc7-67 ste12- $\Delta 1:: U R A 3)$. All gene replacements were confirmed by Southern blot analysis.

Diploid strain E905 was constructed by mating strains

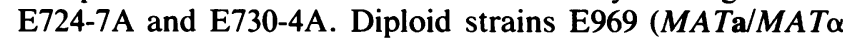
CYC7-H2/CYC7-H2) and E970 (MATa/MAT $\alpha$ CYC7-H69/ CYC7-H69) were constructed from E724-7A-1 and E724-7A5 , respectively, by use of a plasmid-borne copy of the $\mathrm{HO}$ gene (YCp50::HO). E969 and E970 were cured of the $\mathrm{HO}$ plasmid prior to analysis. To verify genetic composition at $M A T$ and other loci, each strain was sporulated and subjected to standard pedigree analysis.

The $\mathrm{LiCl}$ procedure was used for all yeast transformations (24). Genetic procedures are described by Sherman et al. (38).

Determination of iso-2-cytochrome $c$. Cells were grown as a narrow line under derepressing conditions on solid YPS medium ( $1 \%$ [wt/vol] yeast extract, $2 \%$ [wt/vol] peptone, $1 \%$ [wt/vol] sucrose, $2 \%$ [wt/vol] agar). Intact cells were examined at $-196^{\circ} \mathrm{C}$ for cytochrome $c$ content with a wavelength prism spectroscope (39).

Preparation of yeast cell extracts. Strains E724-7A-5, E7247A-6, E724-7A-8, and E905 were used for preparation of extracts by the method of Pfiefer et al. (33) with some modifications. Cells were grown in liquid YPD medium (1\% [wt/vol] yeast extract, $2 \%$ [wt/vol] peptone, $2 \%$ [wt/vol] glucose) to a density of $2 \times 10^{7}$ to $3 \times 10^{7}$ cells per ml. Cells were then harvested and washed with 0.01 volume of extraction buffer [ $200 \mathrm{mM}$ Tris hydrochloride $(\mathrm{pH} \mathrm{8.0),} 400 \mathrm{mM}$ $\left(\mathrm{NH}_{4}\right)_{2} \mathrm{SO}_{4}, 10 \mathrm{mM} \mathrm{MgCl}$, $1 \mathrm{mM}$ EDTA, $10 \%$ glycerol, 1 $\mathrm{mM}$ phenylmethylsulfonyl fluoride (PMSF), $7 \mathrm{mM}$ 2-mercaptoethanol (2-ME)]. The cell pellets were suspended in 0.001 volume of extraction buffer. Cells were disrupted with a vortex mixer in the presence of an equal volume of glass beads $(0.45-\mathrm{mm}$ diameter). The lysed cells were incubated for an additional $30 \mathrm{~min}$ on ice. Cell debris was pelleted with the glass beads by centrifugation. The supernatant was subjected to further centrifugation for $1 \mathrm{~h}$ at $13,000 \times \mathrm{g}$. Saturated $\left(\mathrm{NH}_{4}\right)_{2} \mathrm{SO}_{4}(100 \%)$ in buffer $(20 \mathrm{mM}$ HEPES [ $N$-2-hydroxyethylpiperazine- $N^{\prime}$-2-ethanesulfonic acid] [pH 8.0], $5 \mathrm{mM}$ EDTA) was added to the supernatant fraction to give a final $\left(\mathrm{NH}_{4}\right)_{2} \mathrm{SO}_{4}$ saturation of $40 \%$. This mixture was incubated at $4^{\circ} \mathrm{C}$ with gentle agitation for $30 \mathrm{~min}$. The protein precipitate was pelleted by centrifugation at $4^{\circ} \mathrm{C}$ for $10 \mathrm{~min}$ at 
$13,000 \times g$. The final protein pellet was suspended in 0.00025 volume of protein buffer (20 mM HEPES [pH 8.0], $5 \mathrm{mM}$ EDTA, $7 \mathrm{mM}$ 2-ME, $1 \mathrm{mM}$ PMSF, 20\% glycerol). The extracts were stored at $-70^{\circ} \mathrm{C}$. Protein concentrations were determined by using the Bio-Rad Laboratories (Richmond, Calif.) protein assay kit.

Probes. Either pNC156 or pNC157 was the source of various region $\mathrm{A}$ fragments from the $\mathrm{CYC7}-\mathrm{H} 2 \mathrm{Ty} 1$. Either pNC154 or pNC155 was the source of various region $A^{*}$ fragments from the variant Ty1. Radioactive probes were prepared by end labeling DNA fragments with polynucleotide kinase and $\left[\gamma^{32} \mathrm{P}\right]$ ATP by standard methods (27). Typical specific activities obtained ranged from 20,000 to 70,000 cpm/ng of DNA.

Gel electrophoresis and DNA-binding analysis. ProteinDNA-binding reactions and electrophoretic fractionation of complexes were carried out as described by Pfiefer et al. (33) with some modifications. Binding reactions were carried out in a $20-\mu \mathrm{l}$ volume containing $0.5 \mathrm{ng}$ of probe DNA and $60 \mu \mathrm{g}$ of protein in binding buffer $[4 \mathrm{mM}$ Tris $(\mathrm{pH} 8.0), 40 \mathrm{mM}$ $\mathrm{NaCl}, 4 \mathrm{mM} \mathrm{MgCl}, 1 \mathrm{mM}$ dithiothreitol, $4 \%$ glycerol, $1 \mu \mathrm{g}$ of poly(dI-dC)]. The reaction mixtures were incubated at $30^{\circ} \mathrm{C}$ for $10 \mathrm{~min}$ to allow protein-DNA complex formation. Gels for resolving protein-DNA complexes were $4 \% 30: 1$ polyacrylamide:bisacrylamide gel in TBE $(89 \mathrm{mM}$ Tris, 89 $\mathrm{mM}$ borate, $2.4 \mathrm{mM}$ EDTA). The gels were preelectrophoresed for $4 \mathrm{~h}$ at $180 \mathrm{~V}(20 \mathrm{~mA})$ in TBE buffer. After the reaction mixtures were loaded, the gels were run at $150 \mathrm{~V}$ (10 $\mathrm{mA}$ ) for $4 \mathrm{~h}$. After electrophoresis, the gels were dried and autoradiographed with an intensifying screen at $-70^{\circ} \mathrm{C}$. Conditions for competition experiments were exactly the same except that competitor DNAs were added to the reaction mix before addition of the protein extract.

DNase I protection and methylation interference assays. Binding reactions were scaled up fivefold. For DNase I protection assays, reaction mixtures were prepared and incubated as described above. After protein-DNA complexes were formed, a $10-\mu l$ solution of DNase I $(15 \mathrm{ng} / \mu \mathrm{l}$ in $25 \mathrm{mM} \mathrm{CaCl} 2-25 \mathrm{mM} \mathrm{MgCl}_{2}$ ) was added to the reaction mixture and incubated for $30 \mathrm{~s}$ at room temperature. The DNase I reaction was stopped by addition of EDTA to a final concentration of $20 \mathrm{mM}$ and loaded on the gel. For methylation interference assays, the probe DNA was partially methylated by treatment with dimethylsulfate (DMS) as described by Maxam and Gilbert (29). The methylated DNA was then used in the standard preparative binding reactions, and samples were loaded on the gel. After gel electrophoresis, the gels were wrapped with Saran Wrap and exposed overnight at $4^{\circ} \mathrm{C}$. The complexed and free bands were excised from the polyacrylamide gel and cast in a $1 \%$ agarose gel. The DNA was recovered from the gel slices by electrophoresis onto DE-81 paper and eluted by the method of Dretzen et al. (6). Prior to ethanol precipitation, the recovered DNA was extracted with phenol and then was precipitated at $-20^{\circ} \mathrm{C}$ overnight. The DNA pellets were rinsed with cold ethanol. For DNase I samples, DNA was suspended directly in gel-loading buffer $(98 \%$ formamide, $10 \mathrm{mM}$ EDTA, $0.1 \%$ bromophenol blue, $0.1 \%$ xylene cyanol). For DMS samples, the DNA was suspended in $\mathrm{H}_{2} \mathrm{O}$, treated with piperidine as described by Maxam and Gilbert (29), and finally suspended in gel-loading buffer. Cleavage products were fractionated on $8 \%$ polyacrylamide $(20: 1$ polyacrylamide:bisacrylamide) $7 \mathrm{M}$ urea DNA-sequencing gels in TBE buffer.
TABLE 1. Cell-type-specific expression of $\mathrm{CYC7}-\mathrm{H} 2$ and $\mathrm{CYC7}-\mathrm{H} 69^{\prime \prime}$

\begin{tabular}{|c|c|c|}
\hline Genotype & Strain & $\begin{array}{l}\text { Amt of iso-2- } \\
\text { cytochrome }\end{array}$ \\
\hline$M A T \mathbf{a} S T E^{+}$ & CYC7-H2 & 18 \\
\hline$M A T \mathrm{a} S T E^{+}$ & СYC7-H69 & 14 \\
\hline MATa ste $7-\triangle 3:: U R A 3$ & CYC7-H2 & 0.5 \\
\hline MATa ste $7-\triangle 3:: U R A 3$ & CYC7-H69 & 4 \\
\hline MATa ste $12-\Delta I:: U R A 3$ & CYC7-H2 & $<0.5$ \\
\hline MATa ste $12-\Delta I:: U R A 3$ & CYC7-H69 & 0.5 \\
\hline MATa $S T E^{+}$ & $\mathrm{CYC7}-\mathrm{H} 2$ & \\
\hline 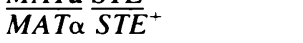 & $\mathrm{CYC7- \textrm {H } ^ { 2 }}$ & 1 \\
\hline$\underline{M A T a}_{S T E^{+}}$ & CYC7-H69 & \\
\hline$M A T \alpha T_{S T E}^{+}$ & CYC7-H69 & 4 \\
\hline
\end{tabular}

" The structure of the $\mathrm{CYC7-H2}$ and $\mathrm{CYC7-H69}$ alleles is shown in Fig. 1. Analysis was performed with two independent isolates resulting from gene replacement or $\mathrm{HO}$ transformation to give the indicated genetic background. The amount of iso-2-cytochrome $c$ is the average of six or more determinations on each isolate. One unit of iso-2-cytochrome $c$ is the amount produced by standard $\mathrm{CYC7}^{+}$strains.

\section{RESULTS}

Cell-type-specific regulation of the Ty1 region $A$ activator. Transcription of Ty1 and Tyl-controlled genes is reduced in a or $\alpha$ haploid cell types with a ste $7-\Delta 3$ or ste $12-\Delta l$ genetic background $(7,9-11,45)$. Experiments were performed to determine whether region A of Ty1 includes cis-acting DNA sequence elements that respond to $S T E 7$ and $S T E 12$ regulation. For these tests, the ability of region $A$ to activate expression of the $C Y C 7$ reporter gene was compared with that of a complete Ty1 insertion at $C Y C 7$. The comparison was made in strains with different $S T E$ genetic backgrounds. Isogenic strains with different $C Y C 7$ alleles were constructed in strain E724-7A (MATa cyc7-67) by gene replacement (Fig. 1). The $C Y C 7-H 2$ fragment used for gene replacement was from pAB35 (9). This fragment contains the cloned $\mathrm{CYC7}-\mathrm{H} 2$ allele in which a Ty1 element is 184 base pairs (bp) upstream from the ATG of the CYC7-coding sequence (12). The CYC7-H69 fragment used for gene replacement is from pNC69. This fragment includes a construction in which Ty1 fragment $\mathrm{A}$ is inserted $200 \mathrm{bp}$ upstream from the CYC7coding sequence (5). Different ste mutant alleles were constructed in the CYC7-H2 and CYC7-H69 strains by gene replacement. The ste $7-\Delta 3$ allele $($ ste $7-\Delta 3:: U R A 3)$ is a deletion of the entire STE7-coding sequence (46). The ste12- $\Delta I$ allele (ste 12- $\Delta I:: U R A 3)$ is a deletion of a fragment that was shown to be sufficient for STEI2 function (15). For both ste mutant alleles, the deleted sequences were replaced with the $U R A 3$ selectable marker.

Comparison of $C Y C 7$ expression was based on the amount of iso-2-cytochrome $c$ produced in various strains (Table 1 ). The $S T E^{+}$CYC7-H69 strain produced $14 \mathrm{U}$ of iso-2-cytochrome $c$ compared with the $S T E^{+} C Y C 7-H 2$ strain that produced $18 \mathrm{U}$. In the ste $12-\Delta I$ genetic background, both CYC7-H69 expression and $\mathrm{CYC7}-\mathrm{H} 2$ expression were reduced to a basal amount of iso-2-cytochrome $c$. This result indicates that region $\mathrm{A}$ includes a key regulatory element of Ty1 which is dependent on the STE12 gene product for function. In the ste7- $\Delta 3$ genetic background, CYC7-H69 expression was reduced 3- to 4-fold, compared with the greater than 18-fold reduction observed for $\mathrm{CYC} 7-\mathrm{H} 2$. We conclude that region A requires the functional $S T E 7$ gene product for activation of $C Y C 7$ expression but that this requirement appears more critical for activation by the complete Ty1. 


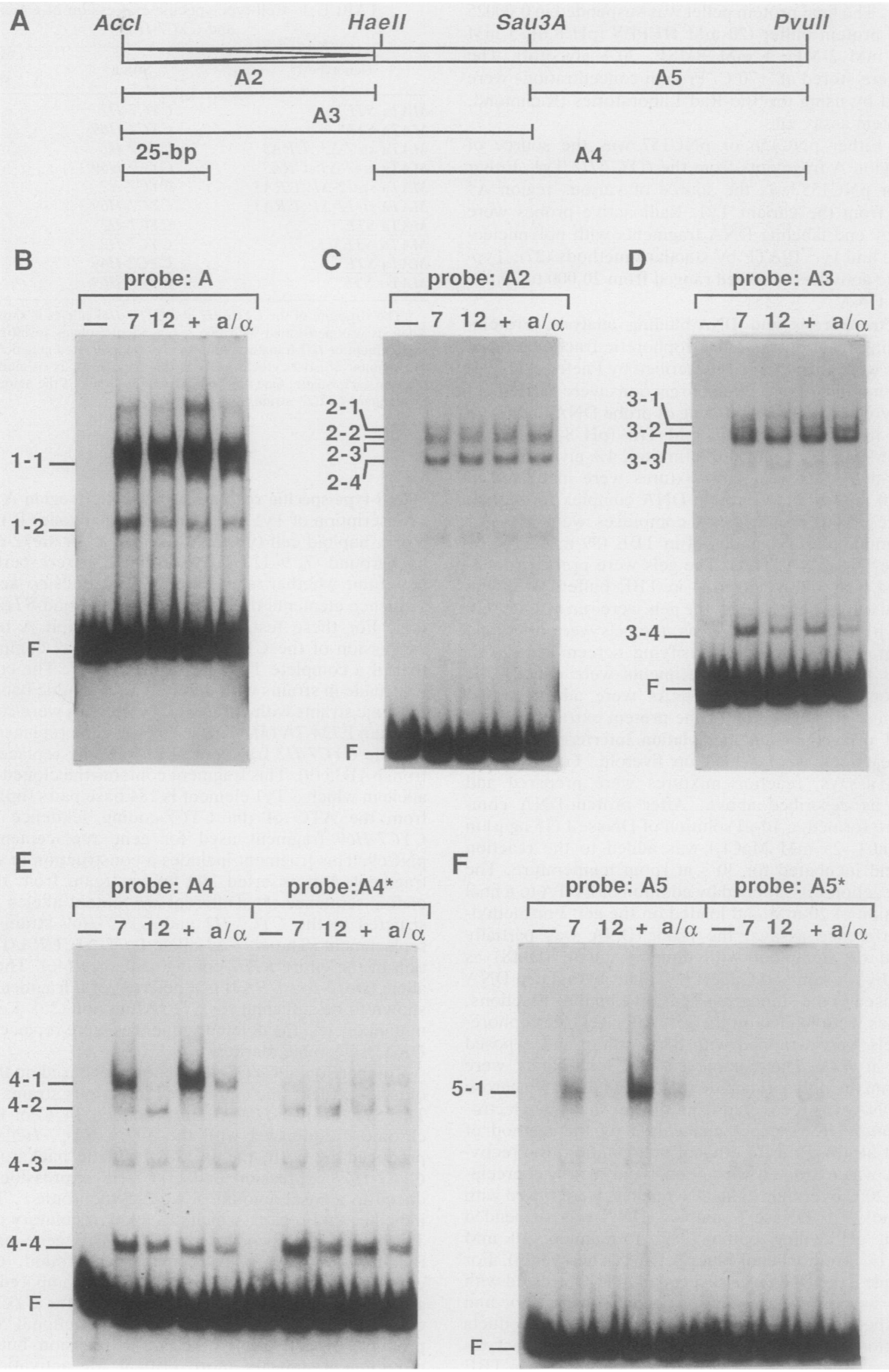




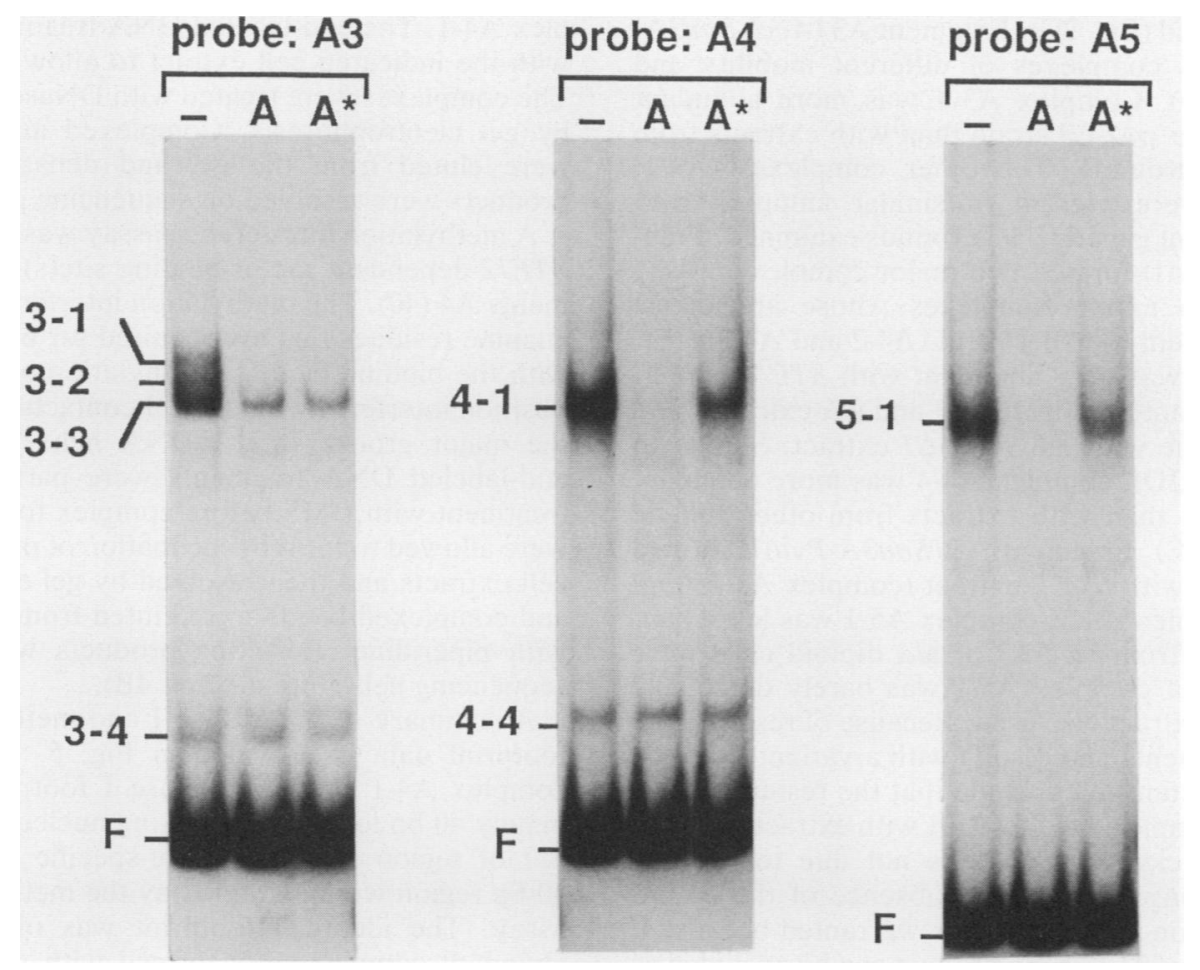

FIG. 3. Competition analysis of factor binding. Binding reactions contained extract ( $60 \mu \mathrm{g}$ of protein) prepared from yeast with a $S T E^{+}$ genetic background. Reactions compared are with no competitor (-) or a 400 -fold molar excess of competitor fragment $A$ or fragment $A^{*}$. as indicated above the corresponding lanes. Base pair differences between fragment $\mathrm{A}\left(\right.$ (CYC7-H2 Ty1) and fragment $\mathrm{A}^{*}$ (variant Ty1) are defined in the legend to Fig. 5. Positions of free (F) and complexed (e.g., 3-1) probes are indicated. The labeled probe $(0.5 \mathrm{ng})$ used in each experiment is indicated. See Fig. 2 for definition of fragments used as probes and competitors.

Our previous analyses with centromeric plasmids indicated that activation of $C Y C 7$ expression by region $\mathrm{A}$ was not significantly repressed in the a/ $\alpha$ diploid cell type (5). A $M A T \mathbf{a} / M A T \alpha$ strain homozygous for $\mathrm{CYC7-H69}$ was constructed to evaluate cell type regulation of $C Y C 7$ expression by region $\mathrm{A}$ when it is stably integrated at the chromosomal locus. Amounts of iso-2-cytochrome $c$ were measured as before (Table 1). Activation of $C Y C 7$ expression by region $\mathrm{A}$ (CYC7-H69) was repressed 3- to 4 -fold in the a/ $\alpha$ cell type compared with the 18-fold repression found with a complete Ty1 $(C Y C 7-H 2)$. It is likely that the decreased activity of the region $A$ activator is an indirect effect resulting from a 5- to 10 -fold reduction of $S T E 12$ expression in the $\mathbf{a} / \alpha$ diploid cell type (15). The more significant repression in $\mathbf{a} / \alpha$ cells found for the complete Ty1 may reflect indirect effects of reduced STE12 expression with additional a1- $\alpha 2$ effects at other cis-acting elements within Ty1 (5).

Detection of proteins that bind to the region $A$ activator. To detect proteins in yeast whole-cell extracts that bind to region $\mathrm{A}$, we used a gel shift mobility assay $(16,18)$. Extracts were prepared from $M A T \mathbf{a}, M A T \mathbf{a} / M A T \alpha, M A T \mathbf{a}$ ste $7-\Delta 3$ and MATa ste $12-\Delta I$ yeast strains. The 211-bp fragment $A$ was $5^{\prime}$ end labeled with ${ }^{32} \mathrm{P}$ and used as a probe for binding activity. Each cell extract contained an activity that resulted in one major band (complex 1-1) with altered electrophoretic mobility (Fig. 2B). Similar amounts of complex 1-1 were observed with all extracts, except for the ste12- $\Delta 3$ extract, which showed a lower amount of binding activity. Addition of excess unlabeled fragment $A$ inhibited complex 1-1 formation (data not shown). Formation of complex 1-1 was not inhibited by including an excess amount of the unrelated Ty1 fragment $D$ in the binding reaction. Excess fragment $A$ or $D$ did not inhibit formation of the minor band (complex 1-2) observed with fragment $A$ as the probe. These results showed that complex 1-1 represents specific DNA-proteinbinding interactions.

Different subfragments from region A (fragments A2, A3, A4, and A5; Fig. 2A) were 5' end labeled with ${ }^{32} \mathrm{P}$ and used as probes in different binding assays. These fragments were analyzed because the presence of multiple regulatory elements throughout region A was suggested by the observation that graduated deletions through this region caused gradual decreases in CYC7 expression (5). Fragment A2 (AcCIHaeII) showed four bands of different mobility and abundance (A2-1, A2-2, A2-3, and A2-4). A given band was present in similar amounts when extracts from each genetic

FIG. 2. Factor binding to Ty1 region A sequences detected by gel mobility shift assays by using yeast cell extracts. (A) Schematic structure of the fragment A probe. Conventions are as defined in Fig. 1. Subfragments A2. A3, A4, and A5, also used as probes, are shown by bars below the diagram. (B to F) Either no extract (-) or extract $(60 \mu \mathrm{g}$ of protein) prepared from yeast with a ste7- $\Delta 3$ (7), stel2- $\Delta l(12)$. $S T E^{+}(+)$, or $M A T \mathrm{a} / M A T \alpha(\mathrm{a} / \alpha)$ genetic background was used in the binding reaction analyzed in the indicated lane. The position of free $(\mathrm{F})$ and complexed (e.g., 1-1) probes are indicated to the left of each panel. Probes used in DNA-binding assays are indicated. (Probes A4* and A5* are from a Tyl with base pair substitutions relative to the CYC7-H2 Ty1: see Fig. 5.) 
background were used (Fig. 2C). Fragment A3 (AccI-Sau3A) also formed several complexes of different mobility and abundance (Fig. 2D). Complex A3-4 was more abundant with extract from the ste $7-\Delta 3$ strain than with extracts from other genetic backgrounds. The other complexes (A3-1, A3-2, and A3-3) were present in similar amounts with extracts from different genetic backgrounds examined. Fragment A4 (HaeII-PvuII) formed two major complexes (A4-1 and A4-4) and two minor complexes whose abundance varied from experiment to experiment (A4-2 and A4-3) (Fig. $2 E)$. Complex A4-1 was very abundant with $S T E^{+}$extract, was reduced significantly with ste $7-\Delta 3$ and a/ $\alpha$ extracts, and was barely detectable with the ste $12-\Delta I$ extract. Similar to complex A3-4 (Fig. 2D), complex A4-4 was more abundant with ste $7-\Delta 3$ extract than with extracts from other genetic backgrounds (Fig. 2E). Fragment A5 (Sau3A-PvuII) formed one major complex with $S T E^{+}$extract (complex A5-1, Fig. 2F). Similar to complex A4-1, complex A5-1 was less abundant when extracts from ste $7-\Delta 3$ or a/ $\alpha$ diploid cells were used. The amount of complex A5-1 was barely detectable when the ste 12- $\Delta l$ extract was used. Because of results from competition experiments and results with a variant Ty1 (see below), we are reluctant to conclude that the residual signal at the position of complex A4-1 or A5-1 with extract from the ste 12- $\Delta l$ genetic background is or is not due to residual activity of the binding factor in the absence of the STE12 gene product. Caution on this point is warranted because it bears on whether the $S T E 12$ gene product can be excluded as a candidate for a binding factor.

Competition analysis was performed to examine the specificity of various complexes observed. The 211-bp fragment A was used as a competitor with different subfragments as radiolabeled probes (Fig. 3). Comparison of reactions without $(-)$ and with (A) competitor showed that excess unlabeled fragment $\mathrm{A}$ abolished formation of complexes A3-1 and A3-2. By contrast, formation of complexes A3-3, A3-4, and A4-4 was weakly or not at all affected by the competitor. Complexes A4-1 and A5-1, whose abundance varied depending on the genetic background of yeast extract, were virtually abolished by the presence of the specific competitor DNA. However, a barely detectable band remained for each complex. The residual signal could be due to incomplete competition even in the presence of a 400 -fold molar excess of competitor DNA. Alternatively, the residual signal may be from a coincident nonspecific complex.

In summary, these results suggest that several different specific DNA-protein complexes were formed throughout region $\mathrm{A}$. The different complexes migrated through the gel with the same mobility when fragment $A$ was used as the probe but were resolved when different subfragments were used. This comparison identified two complexes whose formation was increased in the ste $7-\Delta 3$ genetic background (A3-4 and A4-4). However, formation of these complexes was not inhibited by specific competitor DNA and was not examined further. Formation of two other complexes (A4-1 and A5-1) required the presence of the STE7 and STE12 gene products. These appeared to be specific DNA-protein complexes because their formation was inhibited by the presence of specific competitor DNA.

Identification of protein-binding sites. A DNase I protection assay was used to map the factor binding site(s) for the STE12-dependent protein-DNA complexes observed (17). The assay identifies sequences rendered inaccessible to cleavage by DNase I because of a factor bound at the site. Two different probes were prepared for the top and bottom strands of fragment A4 to map factor-binding sites in com- plex A4-1. The end-labeled DNA fragments were incubated with the indicated cell extract to allow complex formation. The complexes were treated with DNase I and then resolved by gel electrophoresis. Complexed and free DNA bands were eluted from the gel and denatured. The resulting products were resolved on sequencing gels (Fig. 4A and B).

A methylation interference assay was also used to map the STE12-dependent factor-binding site(s) of end-labeled fragments A4 (40). The methylation interference assay identifies guanine residues that are required for base-specific contacts with the binding factor. (Methylation of guanine at the N-7 position interferes with critical contacts made by proteins in the major groove of the DNA helix.) In this assay, the end-labeled DNA fragments were partially methylated by treatment with DMS before complex formation. Complexes were allowed to form by incubation of methylated DNA with cell extracts and then resolved by gel electrophoresis. Free and complexed bands were eluted from the gel and cleaved with piperidine. Resulting products were fractionated on sequencing gels (Fig. 4A and 4B).

A summary of the DNase I and methylation interference footprint data is provided in Fig. 5. With $S T E^{+}$extract, complex A4-1 shows a DNase I footprint region approximately $40 \mathrm{bp}$ long encompassing nucleotide positions 237 to 277 of region $\mathrm{A}$. Three base-specific contacts within this 40-bp region were identified by the methylation interference assay. The identical footprint was obtained for the less abundant complex A4-1 formed with ste $7-\Delta 3$ extract. This result excludes the possibility that the $S T E 7$ gene product makes specific DNA contacts at this site. Several possibilities to account for the lower abundance of the complex with ste $7-\Delta 3$ extracts can be envisioned. One possibility is that the $S T E 7$ gene product directly or indirectly establishes the equilibrium position of the protein-DNA complex. This could result whether the STE7 gene product regulates the affinity of the binding factor for DNA or regulates the abundance of the binding factor.

The DNase I-protected region and methylation interference sites for complex A5-1 formed with $S T E^{+}$extract was determined for the bottom strand. Because the Sau3A cleavage site is at position 238, the DNase I-protected region could be resolved only to position 241 of the nucleotide sequence (Fig. 5). Within positions 241 to 274 , the DNase I-protected and hypersensitive sites were identical to those observed with complex A4-1 (data not shown). In addition, the same methylation interference sites were identified for complexes A5-1 and A4-1 (data not shown). The footprint results, together with the observed effects of STE7 and STE12 genetic background on formation of complexes A4-1 and A5-1, indicate that both are formed by the same proteinDNA-binding interaction.

Role of the STE12-dependent protein-binding site in activation of adjacent gene expression. The results from binding and footprint assays showed that subfragment A5 encompasses a recognition element for a site-specific binding protein(s). This recognition element may be sufficient for the STE7- and STE12-dependent gene activation observed with region A. To test this hypothesis, subfragment A5 was inserted at the polylinker site upstream from the $C Y C 7$ reporter gene in the centromeric plasmid pNC98. The resulting plasmid was designated pNC188. The plasmid pNC105, in which fragment A was inserted at the pNC98 polylinker site, was included in the comparison for reference (5). The iso-2cytochrome $c$-deficient yeast strain E906-8B was transformed with pNC98, pNC105, and pNC188. Amounts of iso-2-cytochrome $c$ produced by transformed strains were 
A

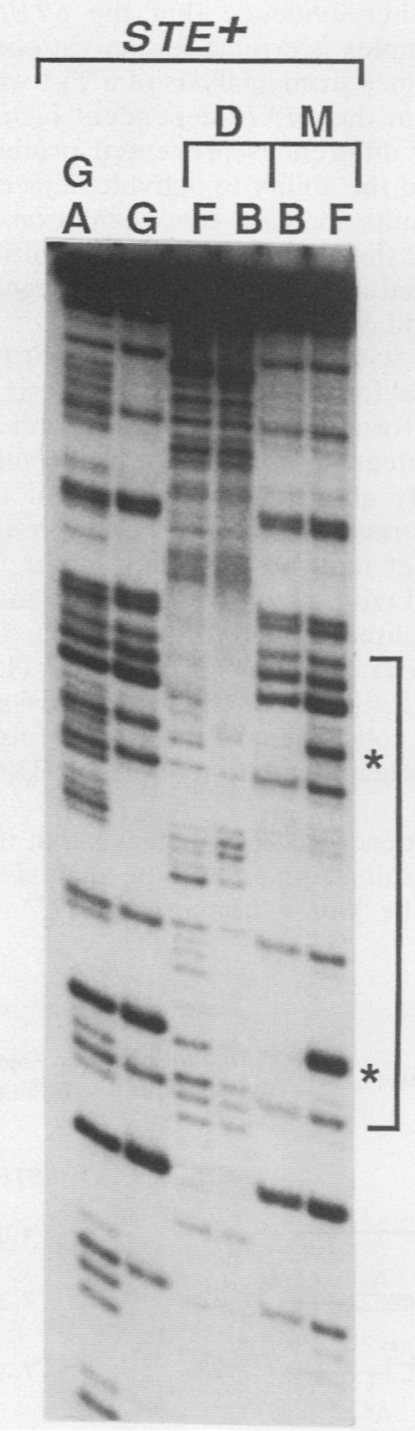

\section{TOP STRAND}

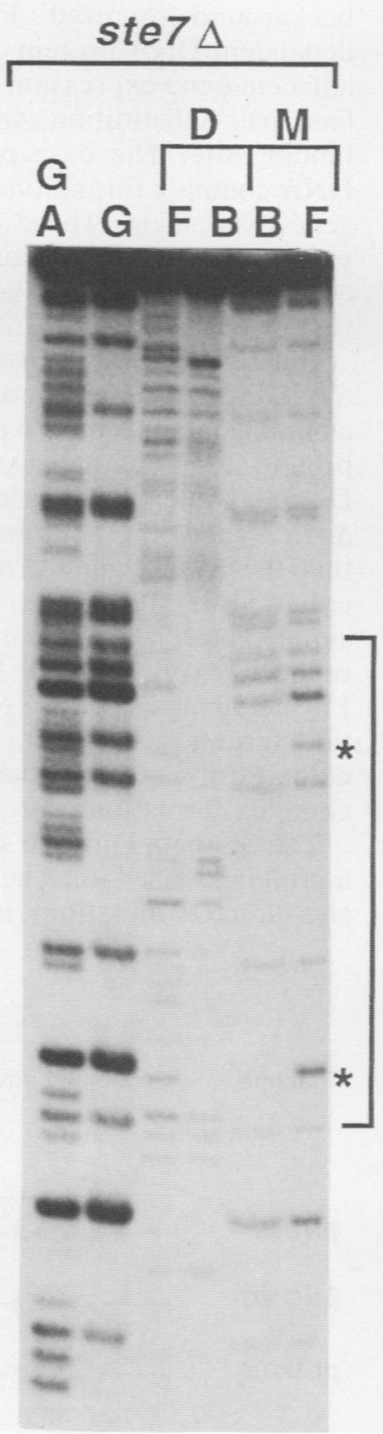

BOTTOM STRAND

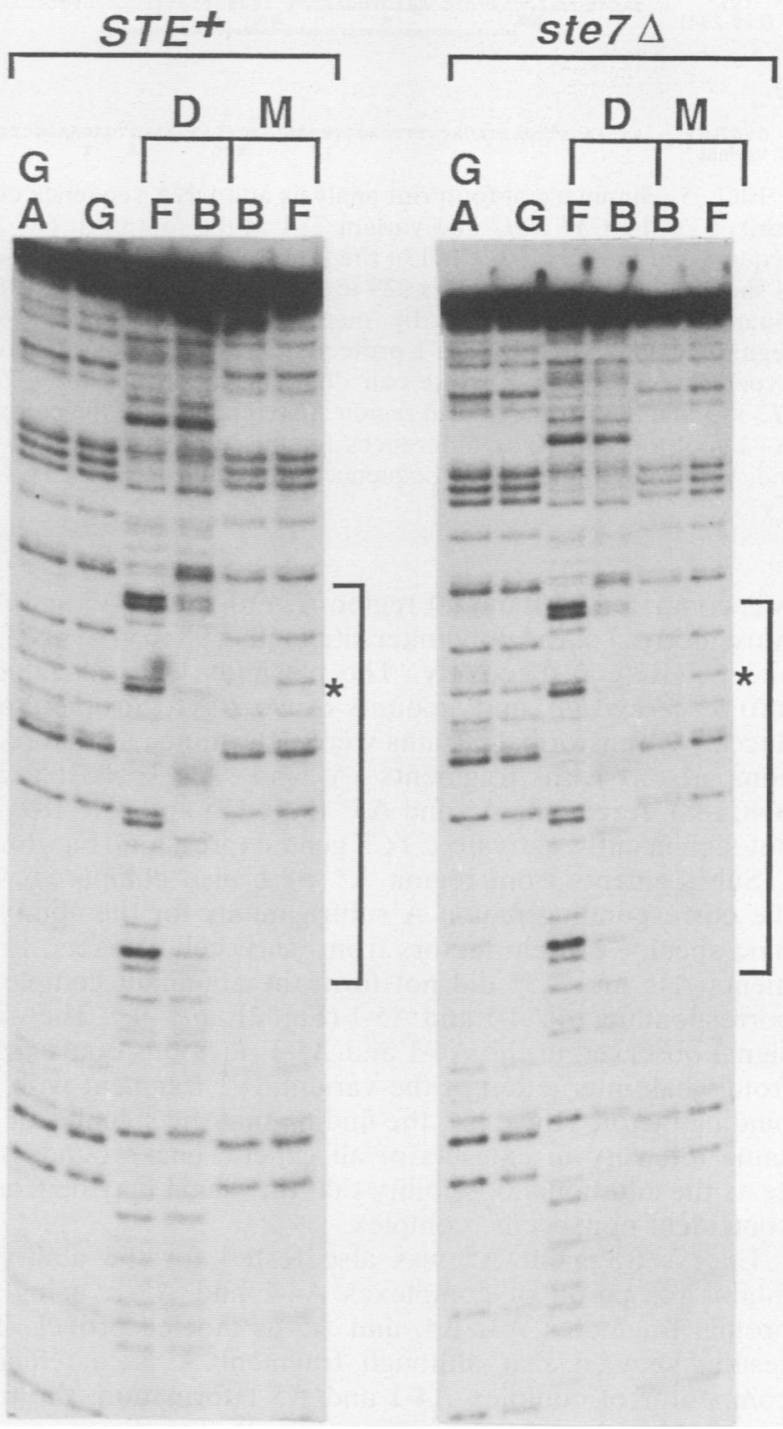

FIG. 4. DNase I protection and methylation interference analysis of factor binding. The top (A) or bottom (B) strand of fragment A4 was specifically end labeled and used as probe DNA. (Fragments are defined in Fig. 2 and 5.) Extracts from yeast with a $S T E^{+}$or ste7- $\Delta 3(s t e 7 \Delta)$ genetic background, as indicated, were used to form complex A4-1 as described in Materials and Methods. D and M above the lanes indicate that DNase I or methylation interference cleavage products, respectively, are displayed. Lanes: F, cleavage products from free probe; B, cleavage products from bound probe (complex A4-1); G and GA, markers generated from probe DNA by Maxam and Gilbert guanine- and purine-specific reactions, respectively. DNase I footprint sequences are shown by brackets. *, Positions of methylation interference.

compared by spectroscopic examination (Fig. 6). Both fragment $\mathrm{A}(\mathrm{pNC105})$ and the subfragment $\mathrm{A} 5$ ( $\mathrm{pNC188)}$ caused a 7.3-fold activation of $C Y C 7$ reporter gene expression compared with the control (pNC98). In contrast, subfragment A5 (pNC188) caused little (1.3-fold) activation of $C Y C 7$ reporter gene expression in strain E906-8B-8 which carries the ste 12- $\Delta I:: U R A 3$ allele. Ability of fragment A5 to activate reporter gene expression in the ste $7-\Delta 3$ genetic background was not tested. However, results from protein-binding experiments (see above) showed that STE7 and STE12 exert their effects at the same site. We conclude that fragment A5 is a STE12-dependent activator of adjacent gene expression.

A reasonable prediction is that the DNA-protein interaction is important for gene activation observed with fragment
A5. A comparison of the normal and base pair substitution derivatives of the DNA recognition element for the ability to activate gene expression in vivo and to bind specific protein factors in vitro offers a direct test of the prediction. For this purpose, a variant Ty1 element that has been isolated and sequenced in the laboratory was analyzed. Within region $\mathrm{A}$, the variant element is identical in sequence to the Tyl analyzed above except at five nucleotide positions. The base pair differences between the two region $A$ fragments are clustered at the footprint for the $S T E$-dependent protein factor (Fig. 5). For simplicity, the variant region $\mathrm{A}$ will be indicated by $A^{*}$. (The details of isolation and characterization of the variant Ty1 are to be published elsewhere.)

The ability of region $\mathrm{A}^{*}$ to activate $C Y C 7$ gene expression 


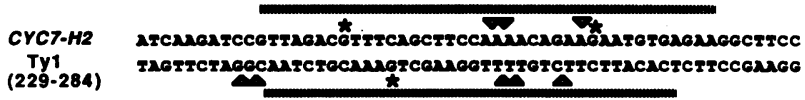

B.

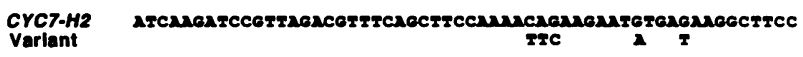

FIG. 5. Summary of footprint analysis and DNA sequence comparison of the $\mathrm{CYC}-\mathrm{H} 2$ and variant Tyl at the footprint. (A) The sequence of the CYC7-H2 Ty1 at the footprint site of complex A4-1 is shown (nucleotide positions 229 to 284 are from reference 12). *, Guanine residues identified by methylation interference; region encompassing DNase I protected sites; $\triangle$ and $\nabla$, DNase I hypersensitive sites. (B) Base pair differences between the CYC7$H 2$ Ty 1 and the variant Ty1 in region A are confined to the complex A4-1 footprint site. The differences found for the variant Tyl are indicated directly below the sequence (top strand) of the $\mathrm{CYC} 7-\mathrm{H} 2$ Ty1.

was compared with that of region A. Fragments $\mathrm{A}^{*}$ and $\mathrm{A} 5 *$ were inserted at the polylinker site in pNC98 to give pNC175 and $\mathrm{pNC} 189$, respectively. The plasmids were introduced into $S$. cerevisiae, and amounts of iso-2-cytochrome $c$ produced by transformed strains were determined as before. In comparison with fragments A and A5 (pNC105 and pNC188), fragments $A^{*}$ and $\mathrm{A}^{*}$ (pNC175 and pNC189) did not significantly activate $C Y C 7$ gene expression (Fig. 6).

Subfragments from region $A^{*}$ were also compared with the corresponding region A subfragments for the ability to bind specific protein factors from yeast cell extracts. Fragments $\mathrm{A} 4^{*}$ and $\mathrm{A} 5^{*}$ did not form the abundant complexes corresponding to A4-1 and A5-1 (Fig. 2E and 2F). The weak signal observed at the A4-1 and A5-1 positions could result from weak interaction of the variant Ty1 fragment with the binding factor. However, the finding that the signal is of the same intensity in extracts of all genetic backgrounds suggests the additional possibility that the signal may be from a coincident nonspecific complex.

Excess fragment $A^{*}$ was also tested for the ability to inhibit formation of complexes A4-1 and A5-1, using the normal fragments $\mathrm{A} 3, \mathrm{~A} 4$, and $\mathrm{A} 5$ as labeled probes. The results showed that although fragment $A$ is an efficient competitor of complex A4-1 and A5-1 formation, the fragment $A^{*}$ was a poor competitor (Fig. 3). The direct correlation between the ability of a specific DNA sequence to activate adjacent gene expression and its ability to bind protein factors indicates that specific protein binding at the DNA recognition element in region $A$ is crucial for its gene activation function.

\section{DISCUSSION}

The STE7 and STE12 gene products are required for full expression of some genes selectively expressed in the a and $\alpha$ cell types of $S$. cerevisiae $(9-11,14,45)$. We showed that these two gene products control the formation of a specific complex between a Ty1 DNA sequence element that is an activator of adjacent gene expression and protein factor(s) that are present in yeast cell extracts. DNA-protein complex formation, using extracts with different genetic backgrounds, strictly parallels the ability of Ty1 fragments that encompass the recognition element to activate adjacent gene expression (Table 1, Fig. 2, Fig. 6). The DNA-protein complex formed by using extracts from $S$. cerevisiae with a $S T E^{+}$genetic background is absent or reduced to very low abundance when extract from ste12- $\Delta l$ yeast cells is used. The STE12-dependent complex is less abundant when extracts from the $a / \alpha$ cell type or from the ste $7-\Delta 3$ genetic background are used. Further evidence that the STE12dependent DNA-protein complex is critical for activation of adjacent gene expression comes from analysis of a Ty1 with base pair substitutions within the STE12-dependent factorbinding site. The base pair differences prevented proteinDNA complex formation and the ability to activate adjacent gene expression. These results indicate that regulation of protein complex formation at the identified DNA recognition element is intimately involved in the transcriptional regulation of genes under STE7 and STE12 control.

Our results are consistent with the interpretation that the STE 12 gene product is critical for the activity or synthesis of a binding factor required for formation of the $S T E$-dependent protein-DNA complex we detect. If formation of the proteinDNA complex is completely abolished by deletion of the STE12 gene, the additional possibility to be considered is that the STEI2 gene product may be a binding factor. In either case, effects observed with the a/ $\alpha$ cell type are most simply interpreted as an indirect effect resulting from the reduced expression of $S T E 12$ in the a/ $\alpha$ cell type (15). Further analysis of the $S T E 12$ gene product will be necessary to determine whether it is a component of the DNA-protein complex or has some other role in regulation of protein-DNA complex formation.

The predicted protein sequence of STE7 suggests that it is a protein kinase (46). The results from phenotype analysis of site-directed mutations in the kinase domain of STE7 are

\begin{tabular}{|c|c|c|c|}
\hline \multirow[t]{2}{*}{ Plasmid } & Schematic structure & $\begin{array}{c}\text { Amount of } \\
\text { cytochrome c }\end{array}$ & $\begin{array}{c}\text { Fold- } \\
\text { Activation }\end{array}$ \\
\hline & & STE + & STE + \\
\hline pNC98 & & 3 & 1.0 \\
\hline pNC105 & & 22 & 7.3 \\
\hline pNC188 & & 22 & 7.3 \\
\hline pNC175 & & 4 & 1.3 \\
\hline \multirow[t]{2}{*}{ pNC189 } & & 5 & 1.6 \\
\hline & & ste12 ${ }^{-}$ & ste12 \\
\hline pNC98 & & 3 & 1.0 \\
\hline VC188 & & 4 & 1.3 \\
\hline
\end{tabular}

FIG. 6. Schematic structure of region A insertions at $\mathrm{CYC7}$ and effects on reporter gene expression. Conventions are as defined in the legend to Fig. 1. The polylinker cloning site of pNC98 is indicated by the broken horizontal line; *, approximate location of nucleotide differences in the variant Ty1 region A (Fig. 5). Amounts of cytochrome $c$ were determined for at least 12 independent isolates from transformation of yeast strain E906-8B $\left(S T E^{+}\right)$or E906-8B-8 (stel2- $\Delta l$, shown as $s t e 12^{-}$) with the indicated centromeric plasmid. The average amounts of cytochrome $c$ are given. One unit is defined as the amount of iso-2-cytochrome $c$ produced by standard strains with the $\mathrm{CYC7}^{+}$allele at the genomic location. Amounts given here are not on a per gene basis. Plasmid copy numbers, generally between 2 and 3. Fold activation is the amount of iso-2-cytochrome $c$ normalized to the amount produced by the pNC 98 control strain. 
consistent with the predicted kinase function (M. Teague and B. Errede, unpublished observations). One model is that the activity of the postulated STE7 kinase is directly or indirectly responsible for phosphorylation of the protein that binds to the regulatory element we have analyzed. According to this model, the phosphorylated form of the protein binds to its specific recognition element with high affinity while the nonphosphorylated protein does not bind or binds with reduced affinity. Our observations do not exclude the alternative possibility that $S T E 7$ regulates expression of the gene encoding the DNA-binding protein or some other critical component for protein-DNA complex formation.

Protein kinases and protein modification by phosphorylation have been implicated in the regulation of gene expression in other systems. For example, treatment of cells with phorbol esters was found to induce binding of specific factors to the $\kappa$ immunoglobulin, simian virus 40 , and polyomavirus enhancers $(1,23,26,36,48)$. It is generally agreed that phorbol esters cause changes in the activity of protein kinase $C$ which then initiates a cascade of events that ultimately affect transcription (32). A heat shock elementbinding protein has recently been purified from yeast cells and found to be phosphorylated under heat shock conditions (44). Although modification of the factor was not required for DNA-binding activity, it was suggested that modification may be required for the formation of a functional transcription complex (43).

Previous studies with any given gene under $S T E$ control showed that mutations of $S T E 7, S T E 11$, or $S T E 12$ cause essentially the same reduction of expression for that particular gene. Also, effects of single or triple ste mutants were found to be identical. To accommodate these observations, it was suggested that the three $S T E$ genes function in the same aspect of transcription rather than being required for independent steps in the process (14). The results presented here suggest that this need not be the case. The ste 7 or ste 12 deletion mutations have an identical effect on gene activation caused by the intact Ty1. However, the effect of the ste 7 deletion is significantly less for the 211-bp region A than for the complete Ty1. One possibility is that STE7 may be involved in the control of multiple factors that recognize distinct regulatory elements in Ty1.

\section{ACKNOWLEDGMENTS}

We are grateful to $\mathrm{S}$. Fields for providing us with the $\mathrm{pSC} 4$ which carries the cloned STEI2 gene and to I. Herskowitz for his gift of YCp50::HO. We thank J. Olson for communicating to us details of procedures for the gel shift mobility assay. We also thank K. Bloom for critical comments on the manuscript.

This work was supported by Public Health Service research grant GM30619 from the National Institutes of Health.

\section{LITERATURE CITED}

1. Angel, P., M. Imagawa, R. Chiu, B. Stein, R. J. Imbra, H. J. Rhahmsdorf, C. Jonat, P. Herrlich, and M. Karin. 1987. Phorbol ester-inducible genes contain a common cis element recognized by a TPA-modulated trans-acting factor. Cell 49:729-739.

2. Bender, A., and G. F. Sprague, Jr. 1987. MAT $\alpha$ l protein, a yeast transcription activator, binds synergistically with a second protein to a set of cell-type-specific genes. Cell 50:681-691.

3. Bolivar, F., R. L. Rodriguez, P. J. Greene, M. C. Betlach, H. I. Heyneker, and H. W. Boyer. 1977. Construction and characterization of new cloning vehicles. Gene 2:95-113.

4. Company, M., and B. Errede. 1986. Transcriptional analysis of Tyl deletion and inversion derivatives at CYC7. Mol. Cell. Biol. 6:3299-3311.

5. Company, M., and B. Errede. 1987. Cell-type-dependent gene activation by yeast transposon Ty1 involves multiple regulatory determinants. Mol. Cell. Biol. 7:3205-3211.

6. Dretzen, G., M. Bellard, P. Sassone-Corsi, and P. Chambon. 1981. A reliable method for the recovery of DNA fragments from agarose and acrylamide gels. Anal. Biochem. 112:295-298.

7. Dubois, E., E. Jacobs, and J. C. Jauniaux. 1982. Expression of the ROAM mutations in Saccharomyces cerevisiae: involvement of trans-acting regulatory elements and relation with the Ty1 transcription. EMBO J. 1:1133-1140.

8. Dynan, W. S., and R. Tjian. 1985. Control of eukaryotic messenger RNA synthesis by sequence-specific DNA-binding proteins. Nature (London) 316:774-778

9. Errede, B., T. S. Cardillo, F. Sherman, E. Dubois, J. Deschamps, and J. M. Wiame. 1980. Mating signals control expression of mutations resulting from insertion of a transposable repetitive element adjacent to diverse yeast genes. Cell 22:427-436.

10. Errede, B., T. S. Cardillo, M. A. Teague, and F. Sherman. 1984. Identification of regulatory regions within the Tyl transposable element that regulate iso-2-cytochrome $c$ production in the CYC7-H2 yeast mutant. Mol. Cell. Biol. 4:1393-1401.

11. Errede, B., T. S. Cardillo, G. Wever, and F. Sherman. 1981. Studies on transposable elements in yeast. I. ROAM mutations causing increased expression of yeast genes: their activation by signals directed toward conjugation functions and their formation by insertion of Tyl repetitive elements. Cold Spring Harbor Symp. Quant. Biol. 45:593-602.

12. Errede, B., M. Company, J. D. Ferchak, C. A. Hutchison III, and W. S. Yarnell. 1985. Activation regions in a yeast transposon have homology to mating type control sequences and to mammalian enhancers. Proc. Natl. Acad. Sci. USA 82: 5423-5427.

13. Errede, B., M. Company, and C. A. Hutchison III. 1987. Tyl sequence with enhancer and mating-type-dependent regulatory activities. Mol. Cell. Biol. 7:258-265.

14. Fields, S., D. T. Chaleff, and G. F. Sprague, Jr. 1988. Yeast STE7, STE11, and STE12 genes are required for expression of cell-type-specific genes. Mol. Cell. Biol. 8:551-556.

15. Fields, S., and I. Herskowitz. 1987. Regulation by the yeast mating-type locus of $S T E I 2$, a gene required for cell-typespecific expression. Mol. Cell. Biol. 7:3818-3821.

16. Fried, M., and D. M. Crothers. 1981. Equilibria and kinetics of lac repressor-operator interactions by polyacrylamide gel electrophoresis. Nucleic Acids Res. 9:6505-6525.

17. Galas, D. J., and A. Schmitz. 1978. DNase I footprinting: a simple method for the detection of protein-DNA binding specificity. Nucleic Acids Res. 5:3157-3170.

18. Garner, M. M., and A. Revzin. 1981. A gel electrophoresis method for quantifying the binding of proteins to specific DNA regions. Application to components of the Escherichia coli lactose operon regulatory system. Nucleic Acids Res. 9: 3047-3060.

19. Guarente, L., and M. Ptashne. 1981. Fusion of Escherichia coli lac $Z$ to the cytochrome $c$ gene of Saccharomyces cerevisiae. Proc. Natl. Acad. Sci. USA 78:2199-2203.

20. Hall, M. N., and A. D. Johnson. 1987. Homeo domain of the yeast repressor $\alpha 2$ is a sequence-specific DNA-binding domain but is not sufficient for repression. Science 237:1007-1012.

21. Hartwell, L. H. 1980. Mutants of Saccharomyces cerevisiae unresponsive to cell division control by polypeptide mating hormone. J. Cell. Biol. 85:811-822.

22. Herskowitz, I. 1986. Specialized cell types in yeast: their use in addressing problems in cell biology, p. 625-656. In J. Hicks (ed.), Yeast cell biology, Alan R. Liss. New York.

23. Imbra, R. J., and M. Karin. 1986. Phorbol ester induces the transcriptional stimulatory activity of the SV40 enhancer. Nature (London) 323:555-558.

24. Ito, H., Y. Fukuda, K. Murata, and A. Kimura. 1983. Transformation of intact yeast cells treated with alkali cations. J. Bacteriol. 153:163-168.

25. Johnson, A. D., and I. Herskowitz. 1985. A repressor (MAT $\alpha 2$ product) and its operator control expression of a set of cell type specific genes in yeast. Cell 42:237-247.

26. Lee, W., P. Mitchell, and R. Tjian. 1987. Purified transcription 
factor AP-1 interacts with TPA-inducible enhancer elements. Cell 49:741-752.

27. Maniatis, T., E. F. Fritsch, and J. Sambrook. 1982. Molecular cloning: a laboratory manual. Cold Spring Harbor Laboratory, Cold Spring Harbor, N.Y.

28. Maniatis, T., S. Goodbourn, and J. S. Fischer. 1987. Regulation of inducible and tissue-specific gene expression. Science 236: $1237-1245$.

29. Maxam, A. M., and W. Gilbert. 1980. Sequencing end-labeled DNA with base-specific chemical cleavages. Methods Enzymol. 65:499-560.

30. Miller, A. M., V. L. MacKay, and K. A. Nasmyth. 1985. Identification and comparison of two sequence elements that confer cell-type specific transcription in yeast. Nature (London) 314:598-603.

31. Nasmyth, K., and D. Shore. 1987. Transcriptional regulation in the yeast life cycle. Science 237:1162-1170.

32. Nishizuka, Y. 1986. Studies and perspectives of protein kinase C. Science 233:305-312.

33. Pfeifer, K., B. Arcangioli, and L. Guarente. 1987. Yeast HAPI activator competes with the factor $\mathrm{RC} 2$ for binding to the upstream activation site UAS1 of the $C Y C I$ gene. Cell 49:9-18.

34. Rothstein, R. 1983. One-step gene disruption in yeast. Methods Enzymol. 101:202-211.

35. Russell, D. W., R. Jensen, M. J. Zoller, J. Burke, B. Errede, M. Smith, and I. Herskowitz. 1986. Structure of the Saccharomyces cerevisiae $\mathrm{HO}$ gene and analysis of its upstream regulatory region. Mol. Cell. Biol. 6:4281-4294.

36. Sen, R., and D. Baltimore. 1986. Inducibility of $\kappa$ immunoglobulin enhancer-binding protein NF-kB by a posttranslational mechanism. Cell 47:921-928.

37. Serfling, E., M. Jasin, and W. Schaffiner. 1985. Enhancers and eukaryotic gene transcription. Trends Genet. 1:224-230.
38. Sherman, F., G. R. Fink, and J. B. Hicks. 1979. Methods in yeast genetics. Cold Spring Harbor Laboratory, Cold Spring Harbor, N.Y.

39. Sherman, F., and P. P. Slonimski. 1964. Respiration-deficient mutants of yeast. II. Biochemistry. Biochim. Biophys. Acta 90:1-15.

40. Siebenlist, U., and W. Gilbert. 1980. Contacts between Escherichia coli RNA polymerase and an early promoter of the phage T7. Proc. Natl. Acad. Sci. USA 77:122-126.

41. Siliciano, P. G., and K. Tatchell. 1984. Transcription and regulatory signals at the mating type locus in yeast. Cell 37:969-978.

42. Siliciano, P. G., and K. Tatchell. 1986. Identification of the DNA sequences controlling expression of the MAT $\alpha$ locus of yeast. Proc. Natl. Acad. Sci. USA 83:2320-2324.

43. Sorger, P. K., M. J. Lewis, and H. R. B. Pelham. 1987. Heat shock factor is regulated differently in yeast and HeLa cells. Nature (London) 329:81-84.

44. Sorger, P. K., and H. R. B. Pelham. 1987. Purification and characterization of a heat-shock element binding protein from yeast. EMBO J. 6:3035-3041.

45. Taguchi, A. K. W., M. Ciriacy, and E. T. Young. 1984. Carbon source dependence of transposable element-associated gene activation in Saccharomyces cerevisiae. Mol. Cell. Biol. 4: 61-68.

46. Teague, M. A., D. T. Chaleff, and B. Errede. 1986. Nucleotide sequence of the yeast regulatory gene $S T E 7$ predicts a protein homologous to protein kinases. Proc. Natl. Acad. Sci. USA 83:7371-7375.

47. Vieira, J., and J. Messing. 1987. Production of single-stranded plasmid. Methods Enzymol. 153:3-11.

48. Wasylyk, C., J. L. Imler, J. Perez-Mutul, and B. Wasylyk. 1987. The c-Ha-ras oncogene and a tumor promoter activate the polyoma virus enhancer. Cell 48:525-534. 